\section{SOBRE EL CAPITAL ERÓTICO COMO CAPITAL CULTURAL}

\author{
José Luis Moreno Pestaña \\ Universidad de Cádiz, España. \\ joseluis.moreno@uca.es \\ Carlos Bruquetas Callejo \\ Consejería de Salud Junta de Andalucía, España. \\ carlos.bruquetas@juntadeandalucia.es
}

Cómo citar este artículo / Citation: Moreno Pestaña, J. L. y C. Bruquetas Callejo. 2016. "Sobre el capital erótico como capital cultural". Revista Internacional de Sociología, 74 (1): e024. Doi: http://dx.doi.org/10.3989/ ris.2016.74.1.024

\section{Resumen}

La teoría social sigue acordando, de manera creciente, un espacio al cuerpo. Señaladamente, las tesis sobre el capital erótico de Catherine Hakim han puesto en primer plano el valor del cuerpo dentro de las jerarquías sociales contemporáneas. Las interrogaciones de Hakim resultan solidarias con otro conjunto de conceptualizaciones que intentan comprender el valor de la interacción corporal en nuestras sociedades. Discutir el modelo propuesto por Hakim a la luz de la capacidad explicativa de la teoría del capital cultural de Pierre Bourdieu es el primer objetivo de este artículo. El segundo objetivo pretende, utilizando un conjunto de datos empíricos, confirmar si pueden apuntarse vínculos entre los cuidados corporales, la clase social, la clase de edad y el género.
\end{abstract}

\section{Palabras Clave}

Sociología del cuerpo, Sociología de la dominación, Pierre Bourdieu, Catherine Hakim.

\section{ABOUT EROTIC CAPITAL AS CULTURAL CAPITAL}

Copyright: @ 2016 CSIC. Este es un artículo de acceso abierto distribuido bajo los términos de la licencia Creative Commons Attribution-Non Commercial (by-cn) Spain 3.0.

Recibido: 24/01/2014. Aceptado: 30/09/2014. Publicación online: 04/02/16

\section{Abstract}

Social theory is trying, increasingly, to reachanagreement on the body place. Particularlly, the Catherine Hakim's thesis about erotic capital has brought to the foreground the value of the body within contemporary social hierarchies. The Hakim's questions are connected with another set of conceptualizations that try to understand the value of the physical interaction in our societies. The first aim of this article is to discuss the model proposed by Hakim on the light of the explanatory capacity of Pierre Bourdieu's cultural capital theory. As a second goal we wish, enlightened by a set of empirical data, to confirm if it is possible to note down links between body care, social class, age class and gender.

\section{KEYWORDS}

Sociology of Body, Sociology of domination, Pierre Bourdieu, Catherine Hakim. 


\section{INTRODUCCIÓN}

En el presente artículo propondremos una discusión sobre el concepto de "capital erótico" considerando que puede comprenderse mejor si lo incluimos dentro de un capital cultural, que impone sus exigencias fundamentalmente a las mujeres más jóvenes y diplomadas. Presentaremos, en primer lugar, el modelo de Bourdieu para, en segundo lugar, discutir la propuesta de Catherine Hakim, quien defiende la novedad de un capital erótico irreductible al modelo de Bourdieu. Esta es la parte fundamental de nuestro artículo: una reformulación del concepto de capital erótico. Pero no nos detendremos en ese punto. Posteriormente mostraremos, a partir de un análisis (cuyas características iremos introduciendo durante la argumentación) de la Encuesta Nacional de Salud en España, que la formulación resulta consistente con ciertos datos empíricos. Estos muestran la correlación, en lo que a las mujeres respecta, entre diplomas y delgadez -este último, uno de los atributos indudables del capital erótico que puede medirse por el índice de masa corporal-. Finalmente mostraremos cómo la consideración del índice de masa corporal en las diversas profesiones rubrica, con la delgadez como indicador, la creciente tensión corporal entre profesiones feminizadas, no todas ellas ubicadas en las clases sociales más altas. La relativa indeterminación social del capital erótico, dependiente de un cultivo femenino extendido socialmente, encontrará una explicación compatible con la tendencia, relativamente monótona, a acompañar el capital cultural.

\section{LAS FORMAS DE CAPITAL Y LA INCORPORACIÓN}

En su conocida diferenciación entre tipos de capital, Bourdieu (2000: 131-164) distingue capital económi$\mathrm{co}$, cultural y social. Bourdieu propone su modelo con un doble sentido polémico. Por un lado, contra quienes reducen el problema del capital a la economía, arrinconando o guarneciendo en el desinterés el resto de las prácticas humanas. Otro frente lo abre contra el economicismo, y, en este caso, describe prácticas cuya lógica interna censura el cálculo económico explícito. Si un artista o un intelectual persiguen la rentabilidad a corto plazo, serán incapaces de desarrollar más que lo solicitado por las modas del momento $y$, seguramente, encontrarán el repudio de quienes trabajan con una perspectiva más amplia. La economía de los bienes simbólicos de Pierre Bourdieu merece una discusión (antropológica, sociológica y filosófica) que nos aleja de nuestro objetivo y sobre la cual existe una abundante bibliografía. Necesitamos retener esto: todos los ámbitos no son reductibles al cálculo económico estándar. La jurista Deborah L. Rhode (2011: 12-13) accedió a presidir una asociación profesional (de mujeres juristas, para mayor escarnio) y rápidamente le impusieron cambiar su aspecto bajo la supervisión de estilistas. ¿Cuál es el comportamiento económico en ese caso? ¿Aceptar que la apariencia es un currículo implícito pero innegociable de una profesional? ¿O, por el contrario, pensar como abogada y feminista que es una intromisión arbitraria e intolerable? Los mercados culturales y los de las clases altas se superponían en ese caso y nadie iba vestido en esos medios como la profesora Rhode. Esta eligió la lógica de los primeros y comenzó una investigación que concluyó en su excelente libro. En términos de un dilema del prisionero, Rhode prefería no cooperar con la imposición aunque eso le infligiese pérdidas con otras competidoras -que sí explotarían, con ventaja, sus propios recursos eróticos-1.

Vayamos con las clarificaciones que aporta Bourdieu a propósito del capital cultural, y, por tanto, dejaremos a un lado el capital económico y el social. Procede una pequeña consideración antes de continuar. Evidentemente, cualquier forma de capital, en la realidad cotidiana de la vida, se encuentra engarzada en modalidades híbridas: todo recurso concreto, ha señalado Neveu (2012: 355), suele combinar diversos tipos de capitales y no puede reducirse a uno. El capital cultural tiene consecuencias en las redes sociales del sujeto $y$, a menudo, en sus recursos económicos. Cada forma de capital puede reconvertirse en otra, aunque esto puede ser más o menos difícil. Importa, sin embargo, por claridad teórica, no confundirlas: el estilo al vestir, del que se hablará, puede mejorar ciertas redes sociales y demostrar estatus económico, pero ambos (estatus y redes) no presuponen el estilo: de hecho, pueden detentarse sin esa cualificación. ¿Dónde situar los requisitos de belleza y corrección (diversos según los contextos sociales) en el vestir, que se abalanzaron sobre la profesora Rhode al ocupar su cargo? Todo apunta a que dentro del capital cultural.

Veamos cómo. El capital cultural se declina de tres maneras. La primera recubre un capital cultural incorporado. Nadie lo adquiere por delegación, solo el implicado puede hacerlo: Bourdieu pone el ejemplo del bronceado o de un físico musculoso. Para empezar, el individuo debe criarse en un entorno que favorezca el deseo de adquirirlo. No todas las familias favorecen por igual las competencias estéticas, las hay que incluso las reprimen o les adjudican valores subordinados. Por tanto, no todas imponen a los individuos un proceso de formación -más o menos amplio y más o menos bien orientado- para vigilar sus dimensiones corporales o su vestuario. Las restricciones alimentarias, el cultivo de la delgadez en la progenie, como sabe quien estudie la cultura familiar de las trabajadoras, no forman parte, por razones económicas, culturales o morales, del menú de muchas familias. En este punto, insiste Bourdieu, la acción pedagógica de la familia marca las competen-

1 La clave se encuentra en la escala de preferencias desde la que uno juega: se puede preferir la autoestima a ser competente en juegos denigrantes. Sobre la formación de preferencias de segundo orden, véase Domènech (1989: 83-96). 
cias de los individuos en su punto más íntimo, más cercano a lo innato. El carisma corporal, el estilo, no se necesita forzar a Bourdieu, se forja entre los privilegiados en acción pedagógica familiar y permite la incorporación de los valores dominantes en los mercados corporales. La idea de programar actividades compensatorias de la falta de transmisión corporal familiar tiene sus partidarios: un ejemplo, cursos para mejorar el aspecto estético en escuelas de hostelería (Hakim 2012: 213).

Una segunda vertiente del capital cultural es el objetivado. Bourdieu se refiere a la pintura o los libros, susceptibles de ser donados por alguien -no como el bronceado-. Ahora bien, donados o no, solo si se tienen las competencias requeridas podrán disfrutarse y comprenderse. El capital económico puede convertirse en este tipo de capital cultural, pero la utilización del mismo requiere más costes. Los individuos pueden ostentarlo como parte de su patrimonio pero eso no los convierte en culturalmente admirables. Sin incorporar el capital cultural, no puede actualizarse una obra de arte y se corre el peligro de quedar por un inculto pretencioso.

La reconversión del capital económico en cultural, costosa, y que es una de las tareas de descripción fundamentales de toda investigación en este campo, nos permite situar algunos de los beneficios que reportan las competencias estéticas. Una creciente bibliografía (Warhurst y Nickson 2007; Williams y Connell 2010), describe trabajadores con sueldos más que modestos y que, sin embargo, ejercerán de mediadores en el terreno de la moda ante una clientela distinguida. Considerarlos explotados puede ser cierto si pensamos económicamente. Pero sería olvidar el prestigio que proporciona enseñar sobre cómo vestirse o maquillarse. Porque, en nuestro medio, es la ropa o el maquillaje lo que juega el papel de capital cultural objetivado; y, sobre cómo actualizarlo, muchos trabajadores tienen más habilidades que su clientela, por económicamente potentada que sea. Una teoría de los diferentes capitales resulta fundamental para explicar la inversión subjetiva en esos empleos, el refuerzo que adquieren sus trabajadores por más que los sueldos sean, a menudo, ridículos. Nadie valoraría la lógica de la vocación de un becario de investigación haciendo únicamente cálculos salariales. El capital cultural que adquiere le proporciona un prestigio, y la promesa de un futuro, que no se reduce a sus ingresos. Idéntica perspectiva debe emplearse para valorar el empleo de quien, con su incorporación y manejo de un capital cultural, recibe reconocimiento por parte de quienes ganan mucho más que él.

La tercera dimensión del capital cultural es la institucionalizada, aquella que proporcionan las credenciales educativas. Las certificaciones ayudan a que el portador no deba demostrar continuamente sus competencias. En nuestro campo, un ejemplo es la existencia, dentro del sistema educativo español, de módulos de Grado Medio de Formación Profe- sional agrupados, según taxonomías ministeriales, dentro de la familia profesional "Imagen Personal". En tiempos de la LOGSE, incluían los Grados Medios de Técnico en Caracterización, Técnico en Estética Personal Decorativa, Técnico en Peluquería, Técnico Superior en Asesoría de Imagen Personal y Técnico Superior en Estética. Dentro de la familia de Sanidad se encuentra también el de Técnico en Dietética. Ya dentro de los títulos LOE se amplían a seis los grados dentro de la misma familia, que pasan a denominarse Técnico en Estética y Belleza, Técnico en Peluquería y Cosmética Capilar, Técnico Superior en Asesoría de Imagen Personal y Corporativa, Técnico Superior en Caracterización y Maquillaje Profesional, Técnico Superior en Estética Integral y Bienestar y Técnico Superior en Estilismo y Dirección de Peluquería. La dietética desaparece de los grados medios sanitarios ${ }^{2}$. También pueden incluirse, con credenciales más o menos reconocidas, una extensa panoplia de cursos de formación.

\section{UN TRABAJO EMOCIONAL PROFUNDO: EL CAPITAL ERÓTICO}

Un libro agitó recientemente ciertos ambientes, al insistir explícitamente en el valor de los recursos corporales en la actividad cotidiana. Según la socióloga británica Catherine Hakim (2012), existe un tipo de capital, el erótico, que no puede reducirse a la tríada de Bourdieu (capital económico, capital cultural y capital social), aunque se relaciona con ellos y los potencia. Para Bourdieu, como se dijo, pero vale la pena insistir, los tipos de capital pueden convertirse entre sí con más o menos dificultad: así, el dinero puede invertirse en estudios o lecturas, en arte y en bibliotecas y producir capital cultural; las redes sociales, pueden acabar siendo útiles para los negocios. Hakim (p. 32) considera que el capital erótico, dependiente en buena medida del azar biológico, no puede adquirirse con los otros capitales. El capital erótico desafía las jerarquías sociales y pueden poseerlo personas con escasísimos recursos económicos, sociales y culturales. Por lo demás, ciertamente, el capital erótico puede permitir el acceso al resto de capitales, y unido a cada uno de ellos (y a sus eventuales composiciones) los potencia y se potencia.

El capital erótico, aclara Hakim, puede ser masculino y femenino, pero existe una ventaja comparativa para el segundo. Un déficit sexual masculino permanente (explorado por la autora, con discutibles argumentos naturalistas, en el tercer capítulo de su libro) hace que los bienes de consumo eróticos jamás sean suficientes para los hombres. Conscientes de ese déficit, los hombres estigmatizan a las mujeres que se benefician de su belleza corporal. En

2 Véase http://www.todofp.es/todofp/formacion/que-y-como-estudiar/oferta-formativa/familias.html, consultado el 4 de octubre de 2013. 
esa empresa de dominación encuentran el paradójico apoyo de cierto feminismo radical y su fobia a la belleza (2012: 98). Esas presiones impiden que las mujeres tomen conciencia de su potencial en el mercado erótico y usen instrumentalmente su cuerpo. Debido a que las elites sociales no pueden acapararlo, el desdén por el capital erótico es patriarcal (colaboración involuntaria del feminismo radical incluida) y clasista (pues impide que mujeres de clases populares se promocionen por medio de su belleza).

El capital erótico tiene, según Hakim, seis elementos (o siete, si se le añade la fertilidad, apreciada en algunas culturas y periodos históricos). El capital erótico no es idéntico a la belleza física (primer elemento), aunque esta puede ser una parte integrante del mismo. Con ciertos límites, la belleza varía con las culturas y los periodos históricos. Pero la existencia de "feas atractivas" muestra que el esfuerzo permite escapar a la maldición de la naturaleza: de ahí la posibilidad y la legitimidad del trabajo estético. Cuando los tribunales reciban denuncias por discriminación en el trabajo, presentadas por trabajadoras a las que se exige determinado aspecto, argumentarán de modo similar: el aspecto físico puede mejorarse y no supone alterar rasgos naturales como el sexo o los rasgos étnicos. La empresa, pues, tiene la facultad de exigirlo a las trabajadoras (Avery, Craine 2007: 51-55). Un segundo elemento consiste en el atractivo sexual. Mientras la belleza es fotogénica, el atractivo sexual es cinematográfico y nace del aura generada por el cuerpo en movimiento. El tercer elemento deriva de la capacidad para atraer a los demás por medio del don de gentes. El cuarto elemento procede de la vitalidad $\mathrm{y}$, sobre todo, del tono corporal y la buena forma física. El quinto elemento deriva de la inversión en ropa y abalorios. Observa bien la autora que los símbolos de estatus (uniformes, ropa con fuertes marcas de clase) determinan, cada vez menos, esta dimensión debido a la fuerte exposición del cuerpo en la moda. En cualquier caso, dominar los contextos y las distintas maneras de presentarse ayuda a revalorizar el capital erótico. El sexto componente es la habilidad sexual propiamente dicha, algo que, según las encuestas, disfrutan un número restringido de personas. Este componente también resulta susceptible de investigación, trabajo y mejora, aunque en este punto la autora se muestra circunspecta.

Dependiendo de las culturas, de los contextos laborales (diversos en una geisha y un informático), el capital erótico juega un papel mayor o menor aunque en conjunto potencia el resto de los capitales. En nuestras sociedades, la importancia del capital erótico contribuye a individualizar cada vez más las trayectorias sociales por lo cual, según la autora, debe romperse todo tabú y trabajar el capital erótico desde la infancia. Como el capital humano, requiere cierta dotación natural; y con ejercicio, resulta posible, con más o menos éxito, acumularlo. El capital erótico resulta central en todos aquellos espacios donde se funden la vida pública y la privada y donde el cuerpo se convierte en el centro de la interacción profesional: se expande con la economía de servicios, lo que da lugar a un problema de justicia en la retribución de la fuerza de trabajo. Para la autora, muchas mujeres (y muchos hombres) progresan económicamente tanto por sus recursos eróticos como por sus competencias técnicas: por lo segundo les pagan, por lo primero no. Las aptitudes sociales (en las cuales el capital erótico juega un papel) son un componente esencial de intercambios económicos apoyados en el aspecto del trabajador. Hakim aboga por recompensar el gobierno de las competencias comunicacionales y corporales.

La propuesta de Hakim contiene aspectos importantes. Por un lado, se atreve a enumerar los componentes que una sociología de los efectos del cuerpo debe considerar. En ese sentido, sale de las indeterminaciones características de muchas referencias, a menudo vagas, al cuerpo. Puede completarse y discutirse cada uno de los puntos propuestos, pero ayudan a comprender que los recursos corporales no se limitan a las apariencias ni a simples dotes naturales, sino que se radican en lo más íntimo de la personalidad del sujeto. El coste de su adquisición es prolongado. Por otro lado, Hakim recuerda el potencial subversivo del capital erótico: relativamente (y cabe discutir y precisar cuánto) dependiente del azar natural, la reproducción de la estructura de clases resulta amenazada por el mismo ${ }^{3}$. Semejante dimensión explica, en buena medida, un aspecto del trabajo corporal que desentona con otras propiedades del capital cultural, al menos con su variante escolar. Al contrario que el capital cultural, el corporal permite un cultivo menos regulado. El atractivo físico de personas -incluso de zonas enteras del planeta- radicalmente empobrecidas sirve de ejemplo de lo que decimos. Pero incluso ese atractivo depende de la proyección de ciertos estereotipos culturales sobre determinadas morfologías y marcas étnicas ${ }^{4}$. Este aspecto, si se quiere democrático, de los recursos corporales explica las razones de muchas mujeres para cultivarlos. La comercialización del capital cultural estético se realiza por los medios de comunicación, se distribuye en los grupos de pares, en los consejos maternos, en suma, en prácticas de promoción de lo femenino sobre las cuales las mujeres tienen un relativo control autónomo. Dicho lo cual, nadie puede exagerar esta dimensión y Hakim nos recuerda que, con preparación y persistencia, personas poco agraciadas pueden convertirse en atractivas ${ }^{5}$. Y esa

3 Bourdieu recogía ya esta idea. Véase Moreno Pestaña (2004: 164).

4 Véase sobre la construcción de mitos y paraísos sexuales, apoyados en relaciones de dominación y en un nuevo imperialismo sexual, véase Michel Bozon (2002: 85-90).

5 Siempre cabe discutir la existencia de un patrón de belleza general. Las variaciones sociales existen y, por supuesto, el canon de belleza tiene una historia. Pero determinados elementos, por ejemplo la delgadez, se encuentran presentes en 
preparación y persistencia se encuentra al alcance de quienes tienen más recursos y tiempo libre que emplear en su acicalado estético.

Hakim incide en un aspecto básico para comprender los efectos del mercado de trabajo en el cuerpo, tema que ocupará la reflexión empíricamente informada de este artículo. Insistiendo en la pluralidad de dimensiones presentes en el capital erótico, este se convierte en un rasgo central de la personalidad del individuo, lacrándose, si consigue incorporarse en todas sus dimensiones, hasta lo más íntimo. En ese sentido, engarza con la apuesta de un importante artículo de Joanne Entwistle y Elisabeth Wissinger (2006: 774-794), crítico con el concepto de "trabajo estético". El trabajo estético modela el conjunto de la personalidad y, en ese sentido, reclama una gestión compleja de las emociones y una modulación de la personalidad que no se reduce a los instantes en que esta se ofrece al empleador o al cliente. Por tanto, cualquier análisis del trabajo estético debe explicar cómo se adquiere y se mantiene en el trabajador. Y eso, cuando del cuerpo se trata, puede invadir bastante la experiencia personal. En ese sentido, la noción de capital erótico radica las cualidades estéticas en la materialidad del cuerpo en su conjunto y no solo en su apariencia, como si se tratase de un disfraz susceptible de ponerse y quitarse a voluntad.

Sirva como ejemplo la adquisición de habilidades sexuales. Estas tienen clara raigambre física, aunque siempre moldeadas por la capacidad de dominar ciertos códigos y de saber activarlos en las situaciones adecuadas. Incluso dichas habilidades, lo ha mostrado convincentemente Randall Collins (2004: 223-257), surgen de rituales que convierten al sexo, y a las proezas con él relacionadas, en centro de atención. En el sexo, un ser humano o un grupo, cargan emocionalmente una escena y generan profundos rituales de solidaridad, convirtiendo ciertos espacios del cuerpo en productores de emociones compartidas y una densa implicación. Cada época valoró partes del cuerpo humano y los sujetos, más o menos de consuno, transforman sus fijaciones eróticas: así, las piernas, en un tiempo completamente impulsoras del deseo, se acabaron banalizando. La sexualidad, por tanto, depende de modelos de exhibición controlada del cuerpo y de cómo, dado un repertorio de habilidades sexuales disponibles, los seres humanos se concentran con otros en tales actividades. Por lo demás, como sabiamente observa Collins, dedicarse a las hazañas

Occidente desde el siglo XVI. La cuestión se ha interpretado de diferente manera: cierto Foucault como el efecto de un dispositivo de singularización burguesa, Vigarello, por su parte, convierte la preocupación por el cuerpo en símbolo de un ascendente individualismo democrático. Véase un balance de esa literatura en Moreno Pestaña (2010: 37-53). Esto no quiere decir que estar delgado sea en todos los contextos y en cualquiera de sus dimensiones atractivo. Pero lo mismo sucede con cualquier recurso: necesita un contexto específico que lo valorice. sexuales conlleva gastos de tiempo que no están al alcance de cualquiera. Las personas de países pobres, con trayectorias de ascenso social alrededor del sexo, integran múltiples habilidades (de cortejo, de compañía, de empatía por los deseos sexuales ajenos, de aspecto y, evidentemente, de mantenimiento del propio cuerpo) que dependen de su capacidad para manejar e insertarse dentro de símbolos culturales de gran complejidad. La sexualidad puede describirse también como cultivo del capital cultural.

\section{Críticas del modelo de Hakim}

Las virtudes del modelo de Hakim no permiten obviar los múltiples puntos oscuros de su propuesta. Cinco críticas pueden planteársele.

1) Un capital excluyente. La autora ignora la parte oscura del capital erótico: su cultivo impide reforzarse en otros ámbitos. Todos los capitales, y todos los estados del capital cultural, no pueden acumularse a la vez. Ya lo decía, con mucha gracia, Sócrates en La República (404a). Las costumbres de los atletas los convertía en inútiles para cualquier función ciudadana, incluidas las militares: "Se trata de un régimen apto para producir somnolencia y hacer la salud precaria. ¿No has observado que estos atletas se pasan la vida durmiendo y, a poco que se aparten de las normas que les han fijado sufren grandes y violentas enfermedades?". Enrique Gil Calvo (2000: 299) lo explicaba en un magnífico libro: las mujeres pueden pagar su relativa dominación en lo micro (debido a su inversión erótica y su control de las interacciones cara a cara) por su relativa subordinación en lo macro (debido a sus carencias en otros tipos de capital cultural o político). Un exceso de control racional del cuerpo puede endurecerse en un hábito, tan asfixiante, que impide sencillamente experimentar otras facetas de la experiencia. Y no por razones de "obsesión" o de obnubilación psicológica, que también pueden existir; sino por razones eminentemente sociales: no todo el mundo tiene las condiciones sociales y la preparación cultural para estar vigilando su dieta todo el tiempo.

2) Costes afectivos del capital erótico. Hakim considera que las mujeres podían ganar más espacio en la vida social si se les enseñase a cultivar y valerse de su capital erótico. El capital erótico, se decía antes, conlleva costes. Pero instrumentalizarlo también resulta difícil: el cuerpo no es cualquier cualificación que ofrecer como mercancía; y muchas culturas, también bastantes personas en la nuestra, asocian a él un sentimiento de dignidad muy profundo, dañado por la absoluta mercantilización (Neveu 2013: 111). La investigación de Entwistle y Wissinger (2006: 785-786) so- 
bre modelos free-lance propone un ejemplo. Los modelos se debaten entre dos preferencias: ser contratadas como modelos, pero también, y no siempre puede compaginarse, mantener el aprecio de su propio cuerpo. Este configura la raíz de su personalidad: en sus hábitos y sus gustos se encuentra depositada su historia, y con ella la de la gente que aprecian. Y así, consideran lesivo que se les recomiende reducir, eliminar o moldear una parte de su cuerpo.

3) Un maquiavelismo ineficaz. Como señala el punto anterior, resulta complicado convertir las preferencias en utilidad, porque todo ser humano comparte sistemas de valores distintos, a veces fuertemente disociados entre sí. El actor no puede volver conmensurables todos los valores $y$, por tanto, no puede constituir un equivalente desde el que jerarquizar preferencias. Pero además, un actor maquiavélico, si logra salvar el escollo de jerarquizar sus plurales valores, debe establecer reglas lógicas para conseguir sus objetivos. Por ejemplo, al parecer de Hakim, explotar los recursos eróticos para ganar dinero o conseguir avanzar en la carrera. Como explicó Wilfredo Pareto, no es lo mismo ejercer de ingeniero de la resistencia de materiales que de ingeniero de almas ajenas: estas se predicen infinitamente peor (Passeron 1995). Los sujetos sobre los que se pretende actuar no deben percibir que se está utilizando la belleza, por ejemplo, para avanzar en la carrera profesional. Si las mujeres controlan el sexo para que los hombres colaboren con ellas, se entraría en una espiral de previsión maquiavélica que impediría el éxito. Sublimar los intereses demasiado evidentes constituye el sustrato de cualquier relación que no sea exclusivamente mercantil. La ausencia de una teoría diferenciada de los espacios sociales le impide comprender, a Hakim, que no todos los recursos funcionan igual en cualquier mercado. $Y$ eso vale tanto para el trabajador social, el policía o el matemático: determinados territorios exigen de quienes son guapos que justifiquen que además son competentes y que podrían estar allí aunque fueran poco agraciados.

4) Una plasticidad limitada. Hakim parece creer que la plasticidad del cuerpo lo convierte en disponible para los manejos del sujeto. Aristóteles pensaba en el cuerpo como en un esclavo. Pero un esclavo se diferencia de un utensilio, que puede manipularse a voluntad (Aristóteles 1254a; 1255b); para que actúe, el amo tiene que tener cierta amistad con él, lo mismo que el alma debe de considerar las exigencias del cuerpo si quiere servirse de él. A los esclavos hay que convencerlos amistosamente para que actúen como queremos y la edad y el desgaste ponen muchos límites. Un cuerpo esclavizado estéticamente también los pone y controlarlo completamente puede ser más difícil que intentar proezas físicas de un esclavo viejo, enfermo y levantisco. Existe una base afectiva en toda personalidad, esta se encuentra arraigada somáticamente y sin amigarse con ella ningún cálculo puede producir más que desequilibrio: despreciar la comida cuando a esta se encuentran asociadas las imágenes infantiles y amistosas de goce y diversión, no resulta tarea fácil y casi podría decirse que las personas convierten su cuerpo en un campo de batalla (Moreno Pestaña 2010: 253).

5) Los "circuitos de Zelizer" corporales. La autora es enemiga de la gordura e identifica delgadez y belleza. En parte lleva razón y los historiadores describen, ya se aludió antes (nota 5), una dinámica de siglos de valorización creciente de la delgadez y de trabajo cada vez más preciso sobre diversas partes del cuerpo. Con la modernización, la estética hegemónica en las clases altas se dedicó a comprimir el cuerpo, a desguazarlo y a cincelarlo con toda la precisión que cada uno podía. Que esa estética se ha ido extendiendo a las clases populares es cierto, aunque enseguida veremos que las cifras obligan a ser prudentes y a conservar el campo semántico de la palabra hegemonía. Lo hegemónico domina y, precisamente por eso, lo hace sobre prácticas que difieren de las encumbradas. Además si los dominados deciden medirse con el calibre de los dominantes, vivirán en la vergüenza y en el retraimiento. Pero las personas dominadas, aunque no se aíslen en un plano completamente ajeno a las pautas dominantes, gozan de un perfil propio, tienen capacidades para crear instantes de desconexión de las jerarquías y organizar su existencia sin el agobio de medirse con los patrones de los dominantes. Un equilibrio de dominación puede, por lo demás, descompensarse en ciertas áreas del espacio social e invertir el lado positivo y el negativo de la relación. Si no investigara con encuestas por cuestionario, Hakim se daría cuenta de que el valor erótico de la corpulencia (o mejor: qué se define como gordura) cambia, en ocasiones, entre dos calles de una misma ciudad: ella misma asume que un informático y una geisha actualizan especies distintas del capital erótico. Pese a que existe un trabajo enorme por unificar el capital erótico, también, la búsqueda de la distinción, propende en ocasiones a complejizarlo y diseminarlo.

También en cuanto al cuerpo funcionan lo que Randall Collins (2004: 260) Ilama "circuitos de Zelizer". Viviana Zelizer, siempre según Collins, mostró que el dinero necesita determinados circuitos para valorizarse. Por ejemplo, los valores bursátiles no funcionan en las verdulerías o las piedras preciosas no se transforman en moneda sin entrar dentro de un circuito de joyeros. Además de tener una moneda, o una cualificación estética, necesi- 
tamos encontrar microsituaciones concretas donde la gente las perciba como valiosas y puedan transformarse en capital. Idéntico proceso sucede con la conversión de las cualificaciones corporales en algo apreciado y susceptible de ser recompensado. Las encuestas pueden proporcionarnos, como comprobaremos inmediatamente, la prevalencia social de ciertas morfologías corporales sobre otras -por ejemplo, la tendencia a la delgadez entre las clases sociales con superiores credenciales corporales-. Ahora bien, eso no permite unificar arbitrariamente las situaciones concretas. En estas pueden aparecer coyunturas en que determinadas cualificaciones corporales no tengan valor o se vean contestadas. Incluso el desprecio por el capital estético puede convertirse en ciertos ámbitos culturales en signo de autenticidad, de compromiso con valores genuinos. Los mercados concretos no reproducen automáticamente los criterios de valor que reconocen los dominantes. Las morfologías corporales no se encuentran completamente unificadas según los grupos sociales y no caminan al ritmo que marcan estos. Los "circuitos de Zelizer" del capital erótico producen contextos donde las jerarquías habituales se modifican.

\section{EL IMC Y LA ENCARNACIÓN DEL CAPITAL}

En su intento de reactualizar La Distinción de Pierre Bourdieu, con datos contemporáneos, Bennett et al. (2010: 152-169) ven, tras la creciente preocupación por el cuerpo, un aumento del valor del capital cultural incorporado. Este se adquiere durante las primeras prácticas de socialización, fundamentalmente en el seno de la familia, y produce disposiciones básicas de percepción y juicio del mundo. Pueden generarse disposiciones en edades más avanzadas pese a que, obligatoriamente, la producción de nuevos hábitos supondrá acomodarse a los antiguos -si es que estos no pueden ser eliminados-.

En lo que respecta al deporte, los autores constatan un aumento general del tiempo dedicado al mismo entre el año 1975 y el año 2000, aumento que se distribuye de modo desigual según el nivel educativo: "Hay una relación monótona entre clase y participación en el deporte, cuanto más alta es la clase, mayor es la participación. Solo un $25 \%$ de los profesionales no hace deporte alguno, comparada con un $59 \%$ de obreros manuales no especializados. Esto se debe en parte a los recursos materiales disponibles, pero se encuentra más ligado a las diferencias concernientes a las funciones distintas que tiene el mantenimiento del cuerpo" (Bennett et al. 2010: 157).

El mapa cualitativo, y eso le da su valor, ofrece una geografía más compleja. En los grupos focales realizados para el estudio, dos varones de alto nivel educativo contestaron el valor del deporte. Aunque los autores no lo señalan, podría ser un indicador del conflicto entre especies del capital cultural, en el caso, aquellas, más reguladas académicamente, dedicadas a la formación de las competencias técnicas y las que, transmitidas históricamente de manera informal, favorecen el capital erótico y las competencias en la interacción cara a cara. Los autores no analizan el conflicto y concluyen que, en las clases altas, la regulación del cuerpo es una base central de la identidad y proporciona una suerte de mínimo común denominador de dignidad social. Pese a que las obligaciones familiares y laborales pueden obligar a dejar el ejercicio (algo que aparece en las entrevistas), las mujeres con ocupaciones bien pagadas y alto capital cultural hacen ejercicio más a menudo que las mujeres de clase trabajadora: solo el $26 \%$ de las mujeres procedentes de ocupaciones altas y cualificadas renuncian al ejercicio por obligaciones laborales y familiares, lo que llega hasta el $69 \%$ entre las mujeres con ocupaciones rutinarias. El fitness recluta sus participantes entre los más jóvenes, los sectores más educados y las mujeres con ocupaciones de clase media.

La intersección entre género y clase resulta significativa: los grupos sociales más juveniles, más femeninos y con capital cultural más alto tenderán, si los datos indican una tendencia general, a realizar más ejercicio físico. Del mismo modo, existen diferencias importantes respecto a declarar dietas para perder peso: no solo entre hombres y mujeres (12\% frente a un $31 \%$ ), sino también entre mujeres con trabajos más o menos cualificados: estas últimas arrojan una menor proporción. El ejercicio acompaña un mayor uso de la cirugía estética, del bronceado y de los pírsines. Como era de esperar, una mayor concentración en el cuerpo supone inversión en los estilos de ropa: son las mujeres y los hombres con más capital cultural quienes distinguen entre ropa de trabajo, ropa de diario y ropa para las ocasiones especiales. El alto capital cultural inspira también un intento de distinguirse en la manera de vestirse, aunque lo que más surge de las entrevistas es el deseo de no distinguirse y de amoldarse al medio en el que cada uno se mueve.

Existe un indicador clave acerca de cómo se construye el cuerpo "legítimo". La dieta es uno de los síntomas más poderosos de que alguien cultiva su aspecto físico. Implica, por un lado, un alto nivel de regulación, pues atañe a una de las dimensiones más físicas del habitus: no solo el deseo de comer, sino la corrección de los gustos; una alimentación codificada no según el deseo espontáneo, o el hambre, sino a partir de un ideal morfológico testimonia un fuerte autocontrol y, por ende, un capital cultural incorporado.

Un indicador de ese esfuerzo puede encontrarse en el peso y su relación con la altura. Este, por supuesto, depende de la herencia biológica, pero también del control del sujeto: la enorme y creciente industria del adelgazamiento así lo atestigua. Como 
señala Dieter Vandebroeck (2013), las clases sociales tienen distintas capacidades para incorporar los modelos de cuerpo legítimos -o convertir su cuerpo normal en cuerpo legítimo-. En esta importante investigación, se recurre al Índice de Masa Corporal $(\mathrm{IMC})^{6}$ para objetivar las diferencias entre las clases sociales. Vandebroeck constata la existencia de un cuerpo ideal entre hombres y sobre todo mujeres y la tendencia, cuando ascendemos socialmente, a convertirlo en realidad. Pese a todo, el autor concluye que la correspondencia no es automática y que la explicación estadística debe habérselas con excepciones. El enigma sociológico del cuerpo se encuentra en calibrar las excepciones a la norma general. La explicación habitual, también la de Hakim y Bourdieu (ver nota 3), es la genética: los ricos y cultos pueden ser pequeños, gordos y feos.

El asunto inquietó desde muy pronto a las clases dirigentes. Cómo se encarna la diferencia social, cómo la morfología muestra los capitales o el status de que se dispone, fue una preocupación del panfleto antidemocrático del Viejo Oligarca, allá por el siglo V a. C. En su Constitución de los Atenienses se quejaba de que el igualitarismo en el atuendo impedía distinguir a esclavos, metecos y libres. Robin Osborne (2011: 24), profesor de Historia Antigua en Oxford, insiste en la importancia del texto y en la ansiedad que revela: los cuerpos, su aspecto, en la vida cotidiana, no respetan las jerarquías establecidas. Ni nuestra estructura social ni nuestro modo de dominación se parecen a aquel, pero cómo se encarna el poder sigue en el centro de nuestras preocupaciones. No es fácil lograrlo. La distribución compleja del capital erótico impone dos perspectivas diferentes: una que lo vincula con el azar y con la libertad de elección del individuo (caso de Hakim), otra que insiste en la vinculación (que no plena asimilación) del cuerpo legítimo con las clases dominantes (Vandebroeck 2013: 187).

Vamos a intentar ofrecer una respuesta que no desmiente la referida a la herencia, pero que ayuda a precisar los efectos de la estructura social contemporánea. Presentaremos las relaciones entre talla y peso, considerando el IMC contenido en la Encuesta Nacional de Salud de 1993, 2001 y 20117. Al analizar la variación entre distribución social de la delgadez y cuerpo legítimo, propondremos una hipótesis acerca de una parte de las excepciones: nuestros datos permiten visualizar correlaciones entre ocupaciones modestas y bajo IMC. He aquí una de las clave -nos parece- fundamentales para

6 Sobre los límites de la utilización del IMC en las ciencias sociales, ver las consideraciones de Thibaud de Saint Pol (2010: 80-85). Baste decir, por cuestiones de espacio, que es un indicador de delgadez. Que lo sea de salud exige mucha discusión.

7 Todo ello controlando la edad. Nos ceñiremos a dos grupos de edad, de 30 a 44 y de 45 a 64 años, pues su nivel de estudios es el definitivo y las dimensiones de los grupos son adecuadas en las tres encuestas que manejamos. comprender la distribución social del atractivo: la existencia, en la clase trabajadora, de oficios femeninos que reclaman cuidado y atención. Esta será nuestra respuesta: la belleza no depende "únicamente" de la reflexividad de los individuos sino (también o sobre todo) de las coacciones inscritas en la economía de servicios.

Los datos muestran distancias crecientes según el capital cultural, básicamente entre mujeres. EI IMC ha experimentado un incremento general, pero lo hace en mayor medida entre las mujeres de clases populares, mientras que las universitarias se controlan, y las más jóvenes lo hacen más que la generación anterior. En hombres, en la franja de edad entre los 30 y los 44 años, las diferencias son muy pequeñas: algo menos de un punto separa la media del IMC de quienes solo tienen estudios primarios de los universitarios. La distancia aumenta algo cuando pasamos a la franja comprendida entre los 45 y los 64 años. En ese caso, la distancia entre ambas posiciones ronda el punto y medio. Las diferencias no permiten hablar de un marcador indiscutible de distancia fundamental entre las clases (excepto en el caso de las mujeres).

En las mujeres las distancias muestran entidad y han aumentado en los últimos veinte años. Entre los 30 y los 44 años, en 1993, la distancia entre quienes tenían mayor y menor nivel de estudios era de más de dos puntos. El foso se amplía en 2011 y las diferencias superan los cuatro puntos. EI IMC de quienes tienen más credenciales universitarias ha aumentado algo menos de un punto, mientras el de las menos diplomadas ha aumentado más de dos puntos y medio. De los 45 a los 64 años aparecen distancias importantes entre las mujeres universitarias y las de estudios primarios (de más de tres puntos y medio) pero que prácticamente se han mantenido estables a lo largo del tiempo, con un levísimo aumento. El aumento del capital cultural en las mujeres, por tanto, incide claramente sobre su morfología. No resulta extraño que sea, en su caso, donde el componente estético del capital cultural tenga un volumen mayor. Primero, porque tradicionalmente son competencias que les han sido atribuidas en la división sexual de la dominación: son las mujeres quienes, históricamente, entre las clases dominantes, mediaron entre el polo del dinero y el polo de la cultura. Y, la segunda razón, apunta a su papel en la división sexual del trabajo: las mujeres, tendencialmente, pueblan profesiones vinculadas a los trabajos de cuidados e interacción, en las que las cualificaciones estéticas tienen un mayor recorrido.

Similares resultados se obtienen si, en lugar de considerar la media del IMC solo por nivel de estudios, estudiamos las proporciones internas a cada una de las franjas de edad. Pese a que las horquillas estadísticas no siempre recogen espacios de edad compartidos, sí parece sensato pensar que la 
Gráfico 1.

Evolución del IMC medio según estudios y grupo de edad. Hombres.

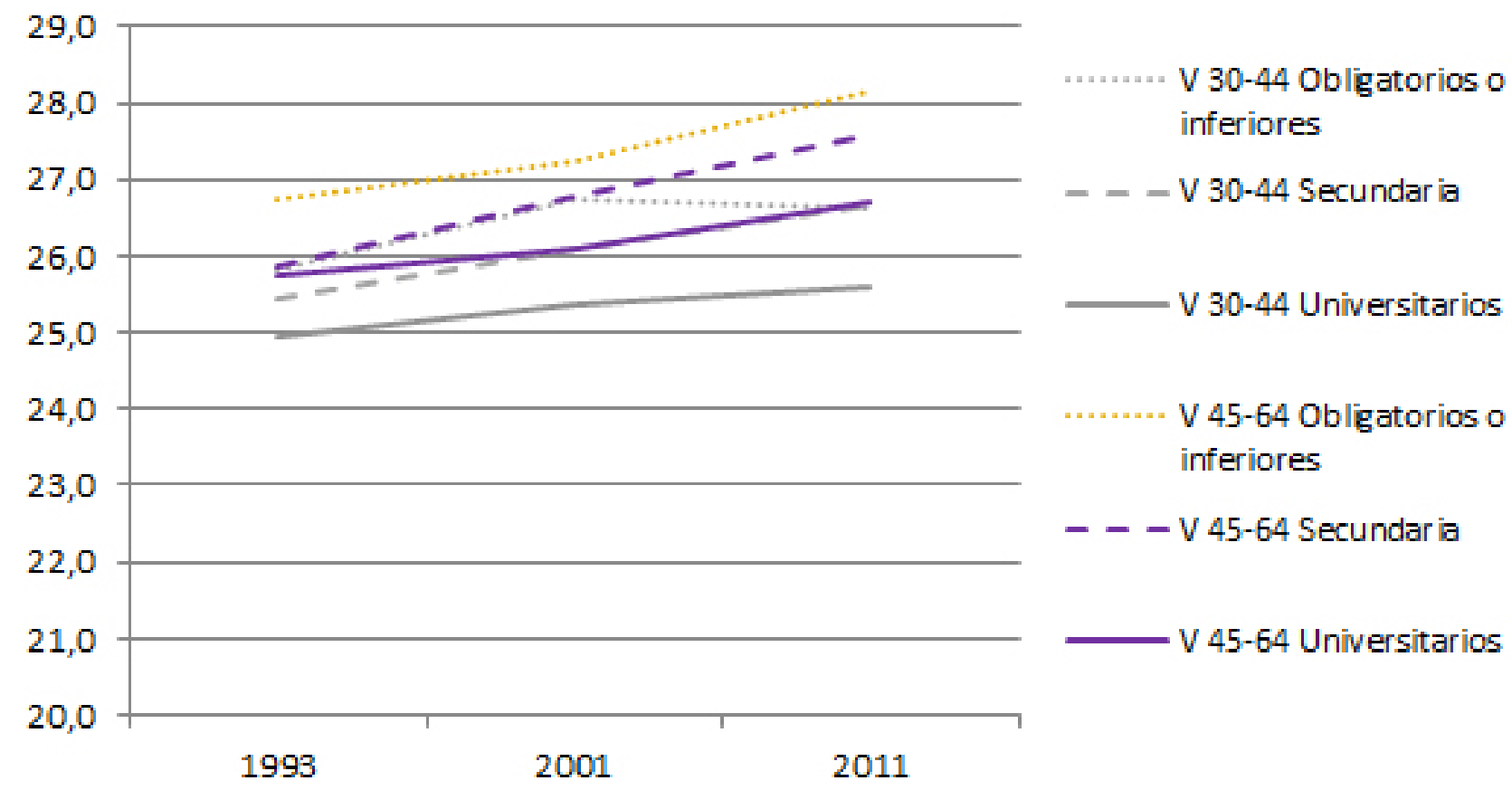

Elaboración propia, a partir de datos de la E.N.S. de 1993, 2001 y 2011.

Gráfico 2.

Evolución del IMC medio según estudios y grupo de edad. Mujeres.

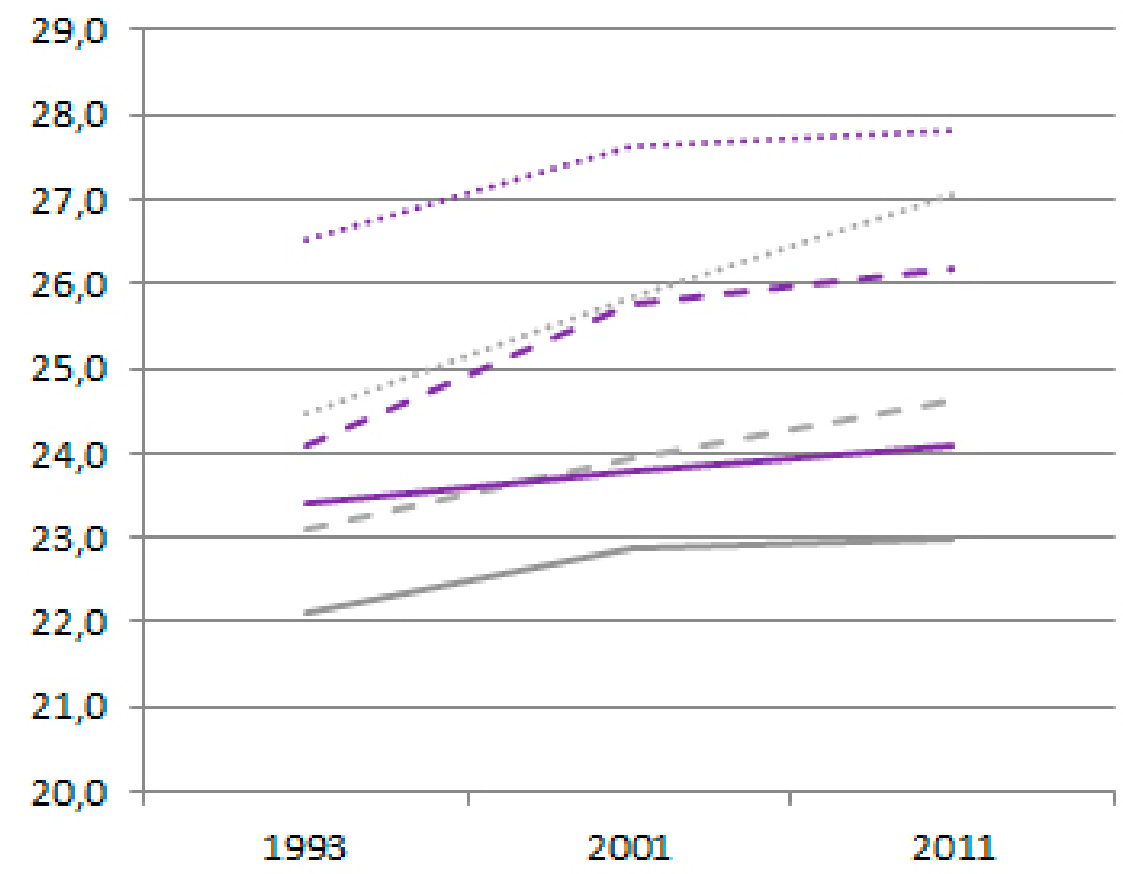

M 30-44 Obligatorioso inferiores

- - - M 30-44 Secundaria

- M 30-44 Univer sitar ios

M 45-64 Obligatorioso inferiores

- - - M 45-64 Secundaria

M 45-64 Univer sitar ios

Elaboración propia, a partir de datos de la E.N.S. de 1993, 2001 y 2011. 
mayoría de las personas se comparan, en cuanto a aspecto corporal y biografía laboral, con los que se encuentran dentro de un radio de edad próximo. Realizaremos la comparación adicionando el normopeso bajo y el peso insuficiente (por tanto, un IMC de 23), siempre centrándonos en mujeres ${ }^{8}$. La mayoría de la población tiene normopeso o peso insuficiente, pese a que la fractura cultural existe: en 1993, estaban delgadas un $66,4 \%$ de las jóvenes con estudios inferiores, cifra que aumentaba hasta el $86,9 \%$ en los estudios superiores. En 2001 las respectivas cifras eran el $50,0 \%$ y el 79,9 \%, y en 2011 hablamos del $38,4 \%$ y el $63,1 \%$. Pero tal vez la composición de edades del grupo joven ha experimentado cambios que justifiquen estas variaciones en la masa corporal. Si atendemos al grupo de edad adulta (30 a 44) donde la inserción y el progreso en el mercado de trabajo comienza a ser apremiante, la diferencia que introducen los estudios es más pronunciada: en 1993, la distancia entre las menos y las más diplomadas, en lo que a delgadez se refiere, era de 25,3 puntos mientras que en 2001 asciende a 34,4 puntos y en 2011 a 43,9. Si las mujeres se comparan prioritariamente con las de su generación, las distancias en las morfologías han ido ampliándose: si consideramos la delgadez un índice de la inversión estética, sin duda, esta tiende a aumentar con el capital cultural.

Lo cual admite dos interpretaciones: la primera que la estructura interna del capital cultural, en lo que corresponde a las mujeres, contiene, sea cual sea el oficio al que se dedican, una proporción mayor de capital estético. La segunda interpretación apunta a que, además del capital cultural requerido por las exigencias del puesto de trabajo, se suma un montante superior de capital cultural dedicado al embellecimiento. En el caso de la primera interpretación, se modificaría la estructura interna del capital cultural femenino, requiriéndose más cualificación estética en detrimento de la "técnica". Si se opta por la segunda, el capital cultural femenino debe ampliar su volumen, incluyendo además de las cualificaciones precisas al puesto, las específicamente estéticas. El feminismo teorizó ese proceso como "requisito de belleza profesional": además de hacer bien su tarea, las mujeres deben cotizar alto en los modelos dominantes de compostura femenina (Wolf 1991).

Gran parte de los conflictos que se tienen en los empleos a propósito del capital estético o erótico se organizan implícitamente desde dicha oposición. Cuando una profesora, una vendedora o una jurista

8 De que tales requisitos no cotizan igual en el caso de los hombres, pueden ser un indicio las distancias en las morfologías. Cojamos el periodo de 2011: la franja de edad más joven reúne el mayor número de hombres delgados entre los que tienen menos estudios -cosa poco significativa porque en esa horquilla (15-29 años) la población con menos estudios es también la más joven-. Entre los 30 y los 44 años la distancia en delgadez entre los que tienen menos y más estudios es de apenas 2 puntos y entre los 45 y los 64 años la distancia es de 1,1 punto. combate los requisitos de belleza profesional, o cuando recibe un halago por satisfacerlos cuenta a su favor con, o debe combatir, un fantasma ideológico: la competencia estética va en detrimento de la técnica.

\section{LAS PROFESIONES Y EL CAPITAL ERÓTICO}

Examinemos ahora la relación entre la ocupación y el índice de masa corporal. De ese modo, tendremos un indicador de qué profesiones se encuentran concernidas por el capital erótico. Lo haremos con los datos de la última Encuesta Nacional de Salud (2011-12), cuyos datos fueron agregados por sectores ocupacionales. A partir de ahí, se exploraron las diferencias en la extensión de personas delgadas ${ }^{9}$ en los 137 sectores incluidos en el análisis ${ }^{10}$. En primer lugar, con los valores extremos como referencia (Tabla 1), pueden visualizarse dos polos. En un lado, las profesiones que reclutan más personas delgadas. Tres son las características que destacan: profesiones ligadas a la salud, o de fuerte exposición corporal, jóvenes y feminizadas -siempre con la excepción de los artistas-. En el otro extremo, las profesiones proletarias y rurales, masculinizadas y maduras.

La relación entre sexo, edad y masa corporal es clara. También lo es la segmentación por sexo y edad del mercado laboral. Las ocupaciones con mayor delgadez son las más jóvenes y femeninas. Una vez establecido el sesgo de género, cabe preguntarse: ¿depende la delgadez solamente de la edad? ¿Son las profesiones con mayor capital erótico, exclusivamente, profesiones femeninas y jóvenes? Es lo que vamos a intentar aclarar a continuación y nuestra respuesta será que depende de la edad pero que, además, correlaciona con el capital cultural.

Un análisis simple de correspondencia (Gráfico 3) confirma que, al agrupar los sectores ocupacionales por su composición de sexo y edad (joven/maduro, masculinizado/feminizado), el segmento "Maduro masculinizado" se acerca a un escaso porcentaje de personas delgadas, y lo contrario sucede con el "Joven feminizado"11. El análisis de varianza (Tabla 2) muestra además coherencia interna en los segmentos.

9 Definida operativamente como la proporción de personas con IMC menor que 23, indicador que puede ser cuestionable y que alternaremos con el que identifica la deldadez con el de normopeso (25).

10 Se han excluido aquellos sectores con base muestral menor a 21.

11 Juventud y feminización relativas: el punto de corte para considerar un sector joven o maduro es la mediana de los promedios, 46,8 años. Respecto de la feminización tomamos la sex ratio total (114). La clasificación de algunos de los sectores en un segmento de sexo y edad se corresponde a una muestra corta para la operación que nos planteamos. Por tanto, aunque los datos se han depurado, lo que aquí se presenta tiene un valor de soporte para la reflexión que no impone conclusiones contundentes. 
Tabla 1.

Porcentaje de personas delgadas de sectores de CNO-2011. Valores extremos.

\begin{tabular}{|c|c|c|c|c|}
\hline & & $\%$ IMC23 & Edad media & Razón de Masc. \\
\hline \multirow{5}{*}{ Mayores } & Otros profesionales de la salud & 61,6 & 38,4 & 76,4 \\
\hline & Maestros y educadores de enseñanza infantil & 55,9 & 37,2 & 4,8 \\
\hline & Trabajadores que atienden a viajeros, guías turísticos y afines & 51,2 & 35,6 & 28,7 \\
\hline & Empleados de información y recepcionistas & 51,1 & 40,9 & 9,2 \\
\hline & Artistas creativos e interpretativos & 49,7 & 42,8 & 189,4 \\
\hline \multirow{5}{*}{ Menores } & Operadores de maquinaria agrícola y forestal móvil & 3,7 & 45,9 & * \\
\hline & Policías & 6,4 & 47,2 & 972,0 \\
\hline & Conductores de camiones & 7,5 & 49,7 & 11798,1 \\
\hline & Trabajadores cualificados ganadería & 8,4 & 62,2 & 190,3 \\
\hline & Trabajadores cualificados en actividades pesqueras y acuicultura & 8,4 & 53,8 & 501,8 \\
\hline
\end{tabular}

Fuente: Encuesta Nacional de Salud 2011-2012. Elaboración propia.

* No se han encontrado mujeres en este grupo ocupacional.

Gráfico 3.

Biplot Estándar* del Porcentaje de personas delgadas y segmentos de sexo y edad.

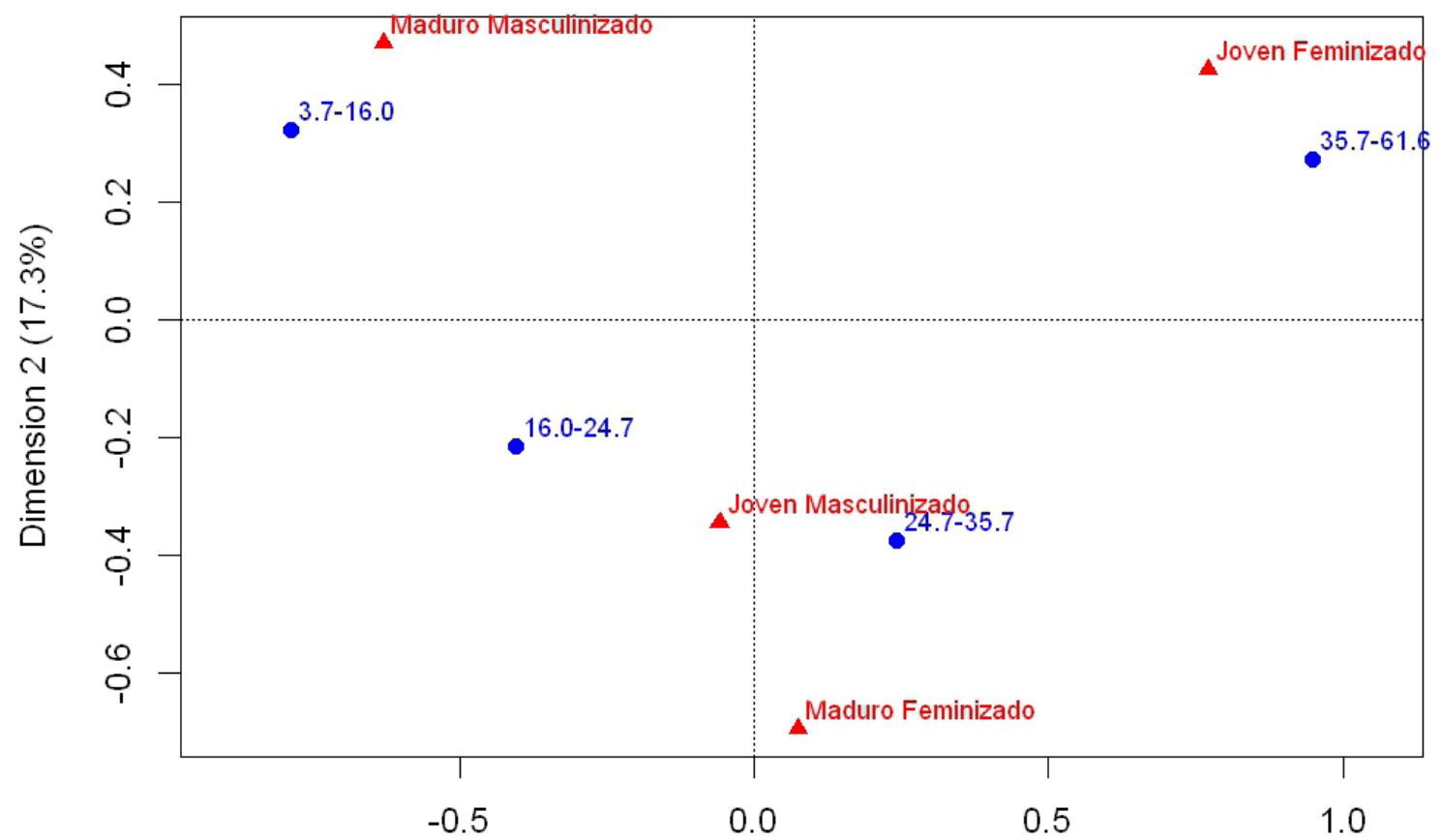

Dimension $1(82.5 \%)$

* Conforme la denominación de Greenacre (2008: 143).

Este gráfico se ha realizado con la librería "ca" de R, de la cual son autores Oleg Nenandic y Michael Greenacre (2007).

Fuente: Encuesta Nacional de Salud 2011-12. Elaboración propia.

Tabla 2.

Análisis de la varianza del porcentaje de personas delgadas en cada sector de CNO-2011 según su composición de sexo y edad.

\begin{tabular}{cccccc}
\hline & Suma de cuadrados & gl & Media cuadrática & F & Sig. \\
\hline Inter-grupos & 9017,348 & 3 & 3005,783 & 35,131 &, 000 \\
\hline Intra-grupos & 11379,537 & 133 & 85,560 & & \\
\hline Total & 20396,885 & 136 & & & \\
\hline
\end{tabular}

Fuente: E.N.S. 2011-12. Elaboración propia. 
En cada segmento hay una distribución bastante dispersa (Tabla 3), pero aún así la representación gráfica nos muestra que existen pautas marcadas $(\text { Gráfico } 4)^{12}$. No solo son diferentes los valores centrales, sino que la función de densidad muestra la heterogeneidad entre las distribuciones. En particular resaltan las diferencias entre "Joven feminizado" y "Maduro masculinizado", prácticamente contrapuestas. Además, en los segmentos "Maduro feminizado" y (sobre todo) "Joven masculinizado" se detectan dos modas, es decir, dos pautas distintas. Como se ve en la siguiente tabla, más que la edad importa el género. Las ocupaciones femeninas y maduras agrupan más personas delgadas que las jóvenes masculinizadas.

Y ¿a qué responde la variabilidad dentro de los segmentos más concernidos? Dentro del "Joven feminizado", a simple vista, la mayor extensión de la delga-

12 El "gráfico beanplot" es una combinación de un gráfico de densidad con otro de caja y bigotes descrito por Kampstra (2008). dez parece ir ligada a las ocupaciones con un mayor capital cultural, en el que destaca, pero no solo, el sanitario (Tabla 4). En el otro extremo encontramos más actividades manuales y de cuidado de personas. Los grupos de sexo y edad, por tanto, se encuentran segmentados internamente: por el aumento del capital cultural pero también, y es muy importante, por profesiones de atención al público que exigen importantes cuidados estéticos. Así, por ejemplo, los ayudantes de cocina, profesión sin exhibición estética, presenta el porcentaje más bajo de personas delgadas.

En un análisis de correspondencias simple dentro del segmento "Joven feminizado", los sectores se agrupan con coherencia en relación a las distintas masas corporales. El modelo explica un $60 \%$ de la varianza total con los dos primeros factores (Tabla 5).

En el Gráfico 5 se verifica una contraposición entre regiones, en las que encontramos, entre el normopeso alto y el bajo, el capital cultural (siempre sanitario) y profesiones de representación: (215) "Otros profesionales de la salud", (225) "Maestros y educadores de

Tabla 3.

Porcentaje promedio de personas delgadas de cada sector de CNO-2011 según su composición de sexo y edad.

\begin{tabular}{lccc}
\hline & Media & N & Desv. típ. \\
\hline Joven feminizado & 39,8 & 30 & 8,9 \\
\hline Maduro feminizado & 27,8 & 23 & 8,4 \\
\hline Joven masculinizado & 24,9 & 39 & 10,9 \\
\hline Maduro masculinizado & 17,6 & 45 & 8,3 \\
\hline Total & 26,3 & 137 & 12,2 \\
\hline
\end{tabular}

Gráfico 4.

Distribución de los sectores ocupacionales por su porcentaje de trabajadores con IMC $<23$, según su composición de sexo y edad.

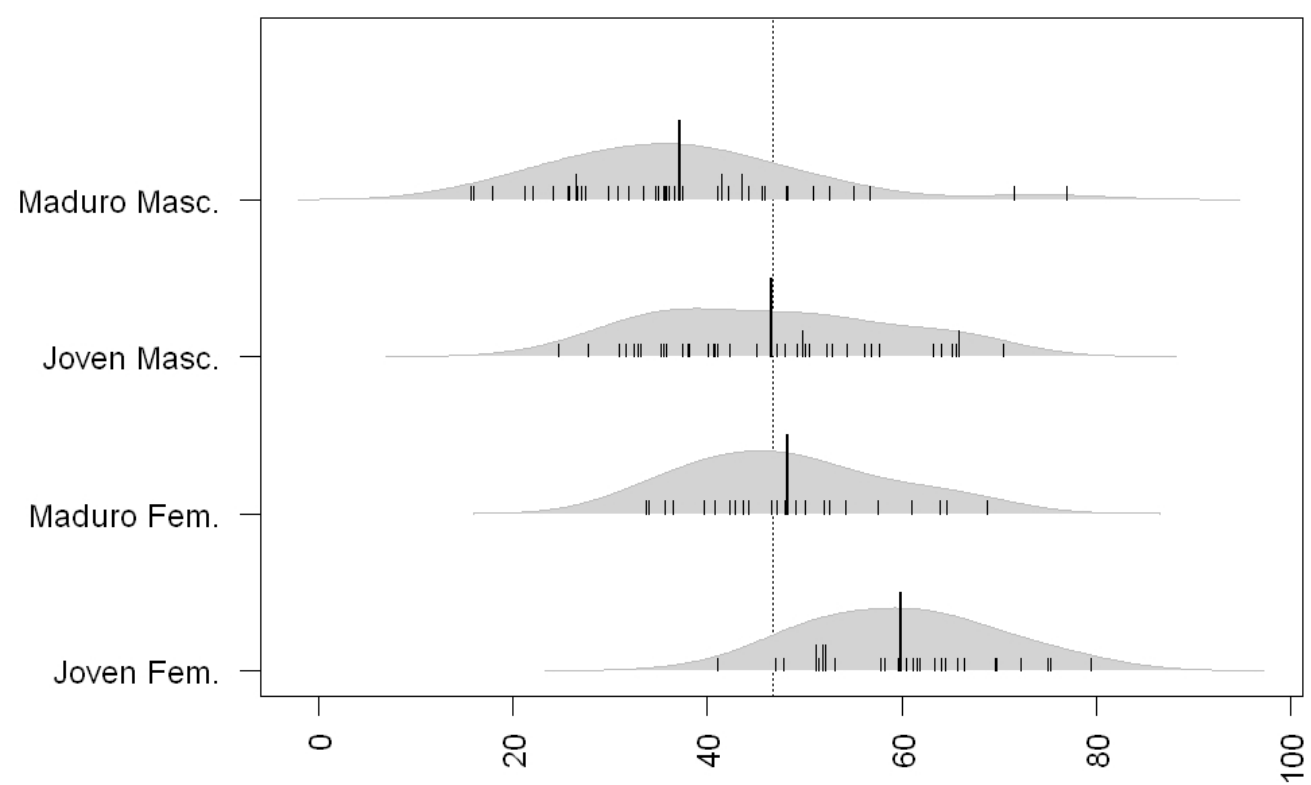

Nota: Este gráfico se ha realizado con la librería "beanplot" de R, de la que es autor Peter Kampstra. Fuente: Encuesta Nacional de Salud 2011-12. Elaboración propia. 
Tabla 4.

Porcentaje de personas con el IMC bajo (<23) y IMC 25 en los sectores del segmento joven feminizado, ENSE- 2011.

\begin{tabular}{|c|c|c|c|}
\hline CNO- 2011 & Literal & $\%$ imc $<23$ & $\%$ imc 25 \\
\hline 215 & Otros profesionales de la salud & 61,6 & 75,3 \\
\hline 225 & Maestros y educadores de enseñanza infantil & 55,9 & 79,5 \\
\hline 582 & Trabajadores que atienden a viajeros, guías turísticos y afines & 51,2 & 72,3 \\
\hline 441 & Empleados de información y recepcionistas (excepto hoteles) & 51,1 & 69,6 \\
\hline 231 & Profesores y técnicos de educación especial & 48,8 & 63,3 \\
\hline 282 & Sociólogos, historiadores, psicólogos y otros profesionales de las ciencias sociales & 48,5 & 64,1 \\
\hline 212 & Profesionales de enfermería y partería & 45,4 & 64,4 \\
\hline 232 & Otros profesores y profesionales de la enseñanza & 44,5 & 69,7 \\
\hline 214 & Farmacéuticos & 43,1 & 66,4 \\
\hline 522 & Vendedores en tiendas y almacenes & 42,1 & 61,6 \\
\hline 331 & Técnicos sanitarios de laboratorio, pruebas diagnósticas y prótesis & 41,1 & 65,7 \\
\hline 242 & Profesionales en ciencias naturales & 41,1 & 58,3 \\
\hline 922 & Limpiadores varios & 40,8 & 59,6 \\
\hline 371 & Profesionales de apoyo de servicios jurídicos y sociales & 40,6 & 75,0 \\
\hline 581 & Peluquería y estética & 40,1 & 60,5 \\
\hline 430 & Administrativos sin atención al público & 39,5 & 60,4 \\
\hline 262 & Especialistas en organización y administración & 39,2 & 52,2 \\
\hline 512 & Camareros asalariados & 39,1 & 61,8 \\
\hline 265 & Otros profesionales de las ventas, la comercialización, la publicidad y las relaciones públicas & 38,3 & 57,8 \\
\hline 450 & Otros administrativos con atención al público & 38,0 & 61,1 \\
\hline 550 & Cajeros y taquilleros (excepto bancos) & 36,4 & 53,1 \\
\hline 561 & Auxiliares de enfermería & 33,6 & 51,5 \\
\hline 816 & Operadores de máquinas para elaborar productos alimenticios, bebidas y tabaco & 33,1 & 51,9 \\
\hline 332 & Otros técnicos sanitarios & 33,1 & 51,9 \\
\hline 572 & Cuidadores de niños & 32,2 & 51,1 \\
\hline 353 & Agentes inmobiliarios y otros agentes & 31,4 & 51,1 \\
\hline 373 & Técnicos de apoyo actividades recreativas & 30,2 & 47,8 \\
\hline 571 & Cuidadores a domicilio (excepto de niños) & 29,4 & 47,0 \\
\hline 442 & Empleados agencias viajes, recepcionistas hoteles y telefonistas & 26,0 & 52,2 \\
\hline 931 & Ayudantes de cocina & 19,5 & 41,0 \\
\hline
\end{tabular}

Fuente: Encuesta Nacional de Salud 2011-12. Elaboración propia.

Tabla 5.

Inercias principales del Análisis de Correspondencia: IMC y sectores ocupacionales del segmento joven feminizado.

\begin{tabular}{lcccccc}
\hline & $\mathbf{1}$ & $\mathbf{2}$ & $\mathbf{3}$ & $\mathbf{4}$ & $\mathbf{5}$ & Total \\
\hline Value & 0,028391 & 0,015986 & 0,013985 & 0,010108 & 0,005553 & 0,074023 \\
\hline Percentage & $38,35 \%$ & $21,6 \%$ & $18,89 \%$ & $13,66 \%$ & $7,5 \%$ & $100,0 \%$ \\
\hline
\end{tabular}

Nota: Elaboración propia a partir de datos de la Encuesta Nacional de Salud 2011-12.

enseñanza infantil”, (441) "Empleados de información y recepcionistas", (231) "Profesores y técnicos de educación especial”, (282) "Ciencias sociales", (212) "Profesionales de enfermería y partería", (371) "Profesionales de apoyo de servicios jurídicos y sociales", y (262) "Especialistas en organización y administración".

En el extremo contrario, en el área del sobrepeso y la obesidad, se encuentra un tercer conjunto de sectores más proletarios: "Técnicos de apoyo actividades recreativas" (373), "Empleados agencias viajes", "Recepcionistas de hoteles y telefonistas" (442) ${ }^{13}$, "Cajeros y taquilleros" (excepto bancos) (550), "Auxiliares de enfermería" (561), "Cuidadores a domicilio" (excepto de niños) (571), "Cuidadores de niños" (572), "Operadores alimentación y tabaco" (816), "Limpiadores

13 Esta ocupación arroja porcentajes muy diferentes a la 441 , aunque se encuentran muy próximas. 
Gráfico 5.

Biplot Estándar del Análisis de Correspondencias: IMC y sectores ocupacionales del segmento joven feminizado.



Dimension $1(38.4 \%)$

Elaboración propia, a partir de datos de la Encuesta Nacional de Salud 2011-2012.

varios" (922), y "Ayudantes de cocina" (931). Respecto al segundo eje, en el que se contrapone el grupo de infrapeso frente a todos los demás, encontramos pocos pero significativos sectores ocupacionales próximos al extremo de baja masa corporal; de nuevo la representación, y las profesiones sanitarias, destacan por su proximidad al IMC bajo: (582) "Trabajadores que atienden a viajeros", "Guías turísticos y afines", (331) "Técnicos de laboratorio" y (214) "Farmacéuticos".

\section{Conclusión}

Presentaremos nuestra conclusión comentando la Tabla 4 (que recoge al sector "Joven feminizado"). Retengamos como indicador que un $60 \%$ de personas con normopeso o peso insuficiente indica la importancia de la delgadez en un empleo. De las dieciséis ocupaciones seleccionadas, tres quedan en la clase social I4: dos ("Farmacéuticos" y "Otros profesionales de la Salud") añaden recursos sanitarios al capital cultural que comparten con la otra clase ("Ciencias sociales"). Dada la estigmatización de la gordura en el discurso dominante sobre salud,

14 De acuerdo con la categoría de clase social ocupacional (Domingo Salvani et al. 2013: 268-269). puede considerarse que tales profesionales se encuentren interpelados por la delgadez. En la clase social II quedan otras cuatro, en la que solo una procede de la salud ("Enfermería y partería") mientras que el resto son diversos profesionales de la enseñanza. La delgadez, en ese caso, podría ser un requisito de coherencia entre el puesto ocupado y la persona: quien cree en lo "científicamente" pernicioso de la gordura intenta, como ejemplo para su público, mantenerse dentro de los límites del IMC. En la clase social III queda una ocupación de atención al público, (582) en las cuales sobrepeso y obesidad podrían eliminar el atractivo físico. En otras dos ocupaciones (dos administrativas, las 430 y 450, y la 371 de apoyo a servicios jurídicos y sociales) no funciona como explicación ni los recursos sanitarios (los cuales podían operar en la 331, "Técnicos sanitarios de laboratorio") ni la atención al público: algo en tales espacios propende a la delgadez, pero solo la investigación cualitativa podría explicarnos el qué. En fin, tres ocupaciones quedan en las clases sociales $\mathrm{V}$ y $\mathrm{VI}$ : una consagrada al trabajo sobre el cuerpo ("Peluquería y estética") y dos profesiones de servicio ("Camareros" y "Vendedores en tiendas y almacenes").

Veamos qué aporta nuestro modelo respecto de esa descripción. Primero, en potencia lógica respecto 
de Hakim. Permite decir lo mismo que esta, integrando sus aportaciones en un marco de comparación más complejo y organizado. Así, entre peluqueros y personal de la estética, un tipo de capital cultural institucionalizado (por ejemplo, títulos de Grado Medio) juega un papel similar al que obtienen las diversas profesiones sanitarias. Ese capital cultural institucionalizado permite la interpretación del capital cultural objetivado (ya sean en un modelo de peinado, ya en un tipo de dieta o consejo de adelgazamiento). En otros grupos profesionales quizá no exista el institucionalizado (por ejemplo, vendedores), lo cual obliga a familiarizarse, con pedagogías informales, con la especie objetivada del capital cultural. En otros casos, el capital cultural institucionalizado o la actividad profesional no parecen tener componente estético alguno. Si las altas tasas de normopeso son, como creemos, indicador de capital erótico, este puede proceder de redes de socialización poco influenciadas por el contenido práctico y el aprendizaje cultural relacionados con la profesión: así, por ejemplo, entre los administrativos.

Nuestra propuesta ayudará a precisar las formas de adquisición, mantenimiento y recompensa del capital erótico, evitando la tendencia del modelo de Hakim a actuar sobre dicotomías: el capital erótico o se tiene o no se tiene, pero siempre influye mejorando la posición de quien lo detenta. Cabe preguntarse cómo se promocionan, se emplean y se relacionan con su cuerpo los profesionales sanitarios con sobrepeso y también, por supuesto, cómo prescinden de la delgadez muchas mujeres trabajadoras que trabajan en profesiones donde la presión parece importante. Un recurso necesita un mercado para convertirse en capital. No cotiza igual en todos los mercados y, en algunos, su posesión es un problema. Hakim contempla esta idea (la estigmatización del capital erótico), pero la atribuye a la influencia cultural de los enemigos de la belleza femenina. El modelo que se propone es diferente. Cada contexto impone normas de lo que es un valor e impone ciertas reglas para adquirirlo. El modelo defendido permite estudiar el juego complejo del capital erótico según las diversas reglas.

Que la teoría del capital erótico tenga valor localizado le hace perder sus ínfulas de generalización e impide que, al teorizar su influencia, hablemos de las mujeres en general; y que ni tan siquiera podamos hacerlo al hablar de las del sector servicios y la de su fracción más juvenil. Un análisis de cada mercado debería, además, continuar precisando el sentido en que el capital erótico entra dentro del cultural: hasta qué punto es correcta la metáfora del capital (¿cómo se acumula el capital erótico), cuáles son las formas de relegación y de promoción en sus procesos de adquisición, por dónde y quiénes lo contestan y se rebelan contra él. Pero eso entra ya en otro trabajo que, a nuestro parecer, no podría realizarse sin este.

\section{Referencias Bibliográficas}

Aristóteles. 2004. Política. Madrid: Gredos.

Avery, D. y M. Crain. 2007. "Branded: corporate image, sexual stereotyping and the new face of capitalism". Duke Journal of Gender Law \& Policy 14:13-123.

Bennett, T. et al. 2010. Culture, class, distinction. Nueva York: Routledge.

Bozon, M. 2002. Sociologie de la sexualité. París: Nathan. Bourdieu, P. 2000. "Las formas del capital. Capital económico, capital cultural y capital social". Pp. 131-164 en Poder, derecho y clases sociales. Bilbao: Desclée de Brouwer.

Collins, R. 2004. Interaction Ritual Chains. Princeton: Princeton University Press. http://dx.doi. org/10.1515/9781400851744

Domènech, A. 1989. De la ética a la política. De la razón erótica a la razón inerte. Barcelona: Crítica.

Domingo-Savani A. et al. 2013. "Propuestas de clase social neoweberiana y neomarxista a partir de la Clasificación Nacional de Ocupaciones 2011". Gaceta Sanitaria 27:263-272. http://dx.doi. org/10.1016/j.gaceta.2012.12.009

Entwistle, J. y E. Vissinger. 2006. "Keeping up appearances: aesthetic labour in the fashion modelling industries of London and New York". The Sociological Review 54:774-794. http://dx.doi.org/10.1111/j.1467-954X.2006.00671.x

Gil Calvo, E. 2000. Medias miradas. Una imagen cultural de la imagen femenina. Barcelona: Anagrama.

Greenacre, M. 2008. La práctica del análisis de correspondencias. Madrid: Fundación BBVA.

Hakim, C. 2012. Capital erótico. El poder de fascinar a los demás. Barcelona: Debate.

Kampstra, P. 2008. "Beanplot: A Boxplot Alternative for Visual Comparison of Distributions". Journal of Statistical Software, Code Snippets 28:1-9, http:// www.jstatsoft.org/v28/c01/, consultado el 12 de enero de 2014

Moreno Pestaña, J. L. 2004. "Cuerpo, género y clase en Pierre Bourdieu”. Pp. 143-184 en Pierre Bourdieu, las herramientas del sociólogo, editado por L. E. Alonso, E. Martín Criado y J. L. Moreno Pestaña. Madrid: Fundamentos.

Moreno Pestaña, J. L. 2010. Moral corporal, trastornos alimentarios y clase social. Madrid: CIS.

Nenadic, O. y M. Greenacre. 2007. "Correspondence Analysis in R, with two- and three-dimensional graphics: The ca packag". Journal of Statistical Software 20 (3): 1-13.

Neveu, É. 2013. «Les sciences sociales doivent-elles accumuler les capitaux? À propos de Catherine Hakim, Erotic Capital, et de quelques marcottages intempestifs de la notion de capital». Revue française de science politique 63:337-358. http://dx.doi.org/10.3917/rfsp.632.0337

Osborne, R. 2011. The history written on the classical greek body. Cambridge: Cambridge University Press.

Platón. 2008. La República. Madrid: Alianza.

Rhode, D. L. 2011. The beauty bias. The injustice of appearance in life and law. Nueya York: Oxford University Press.

Saint Pol, T. 2010. Le corps désirable. Hommes et femmes face à leur poids. París: PUF.

Vandebroeck, D. 2013. "Harnessing the flesh. Social 
class and reflexive embodiment". Tesis doctoral, Departamento Sociología, Universidad Libre de Bruselas, Bruselas.

Warhurst, C. y D. Nickson. 2007. "A new labour aristocracy? Aesthetic labour and routine in interactive service". Work, Employment and Society 21:785-798. http://dx.doi.org/10.1177/0950017007082887

JOSÉ LUIS MORENO PESTAÑA (1970), es profesor de filosofía en la Universidad de Cádiz. Es licenciado y doctor en filosofía, DEA en sociología y titular de una Habilitation à diriger des recherches en sociología en Francia (EHESS, París). Miembro asociado del Centre de sociologie européenne, es el autor de Convirtiéndose en Foucault. Sociogénesis de un filósofo (Barcelona, Montesinos, 2006) traducido al francés como En devenant Foucault. Sociogenèse d"un philosophe (Broissieux, Éd. du croquant, 2006), Filosofía y sociología en Jesús Ibáñez. Genealogía de un pensador crítico (Madrid, Siglo XXI, 2008), Moral corporal, trastornos alimentarios y clase social (Madrid, CIS, 2010) y La norma de la filosofía (Madrid, Biblioteca Nueva, 2013). Ha realizado la traducción y la edición crítica de la obra de Jean-Claude Passeron, El razonamiento sociológico. El espacio comparativo de las pruebas históricas (Madrid, Siglo XXI, 2011). Ha publicado múltiples trabajos en revistas y libros colectivos nacionales
Williams, C. L. y C. Connell. 2010. "“'Looking good and sounding rigth": aesthetic labour and social inequality in the retail industry". Work and Occupations 37:349-377. http://dx.doi.org/10.1177/0730888410373744

e internacionales. Ha coordinado varios libros y números de revistas. Destaca su coordinación del número 208 (junio de 2015) de la revista Actes de la recherche en sciences sociales titulado "Le poids du corps", donde escribe la introducción y un artículo.

CARLOS BRUQUETAS CALLEJO es sociólogo, investigador en la Consejería Salud de la Junta de Andalucía. Anteriormente trabajó como técnico en el Servicio de Estudios, Síntesis y Métodos estadísticos del Instituto de Estadística de Andalucía, en proyectos como la Encuesta Social 2010: Hogares y Educación, y la Encuesta Redes familiares en Andalucía (2005). Sus principales publicaciones son las siguientes: 2011, "Evolución del nivel de salud de los españoles en los últimos treinta años" 2007: "Córdoba: dependencia y solidaridad en las redes familiares"; 2006: "Mujer, mercado de trabajo y conciliación de la vida laboral y familiar en Madrid"; 2004: "Urban Outskirts in Madrid"; y 2001: "Ropa interior masculina". 